\title{
High acceptance of home-based HIV counseling and testing in an urban community setting in Uganda
}

\author{
Juliet N Sekandi ${ }^{1}{ }^{2 *}$, Hassard Sempeera ${ }^{2}$, Justin List ${ }^{3}$, Micheal Angel Mugerwa ${ }^{4}$, Stephen Asiimwe ${ }^{1}$, Xiaoping Yin ${ }^{1}$ \\ and Christopher C Whalen ${ }^{1}$
}

\begin{abstract}
Background: HIV testing is a key component of prevention and an entry point into HIV/AIDS treatment and care however, coverage and access to testing remains low in Uganda. Home-Based HIV Counseling and Testing (HBHCT) has potential to increase access and early identification of unknown HIV/AIDS disease. This study investigated the level of acceptance of Home-Based HIV Counseling and Testing (HBHCT), the HIV sero-prevalence and the factors associated with acceptance of HBHCT in an urban setting.

Methods: A cross-sectional house-to-house survey was conducted in Rubaga division of Kampala from JanuaryJune 2009. Residents aged $\geq 15$ years were interviewed and tested for HIV by trained nurse-counselors using the national standard guidelines. Acceptance of HBHCT was defined as consenting, taking the HIV test and receipt of results offered during the home visit. Multivariable logistic regression analysis was performed to determine significant factors associated with acceptance of HBHCT.
\end{abstract}

Results: We enrolled 588 participants, 408 (69\%, 95\% Cl: 66\%-73\%) accepted testing. After adjusting for confounding, being male (adj. OR 1.65; 95\%Cl 1.03, 2.73), age 25-34 (adj. OR 0.63; 95\% Cl 0.40, 0.94) and $\geq 35$ years (adj. OR 0.30; 95\% Cl 0.17, 0.56), being previously married (adj. OR 3.22; $95 \% \mathrm{Cl} 1.49,6.98$ ) and previous HIV testing (adj. OR 0.50; $95 \% \mathrm{Cl} 0.30,0.74$ ) were significantly associated with HBHCT acceptance. Of 408 who took the test, 30 (7.4\%, 95\% Cl: 4.8\%-9.9\%) previously unknown HIV positive individuals were identified and linked to HIV care.

Conclusions: Acceptance of home-based counseling and testing was relatively high in this urban setting. This strategy provided access to HIV testing for previously untested and unknown HIV-infected individuals in the community. Age, sex, marital status and previous HIV test history are important factors that may be considered when designing programs for home-based HIV testing in urban settings in Uganda.

\section{Background}

Worldwide, HIV counseling and testing (HCT) is a key intervention for HIV prevention and a critical entry point into life-sustaining treatment and care programmes [1-4]. As the scale-up to anti-retroviral treatment access continues to accelerate in Sub-Saharan Africa, innovative strategies to increase access to HCT services should be simultaneously implemented [5]. In the past decade, a variety of HIV counseling and testing approaches have been used, including provider-initiated

\footnotetext{
* Correspondence: juliet.sekandi5@gmail.com

${ }^{1}$ College of Public Health, University of Georgia, Athens, GA, USA

Full list of author information is available at the end of the article
}

testing and counseling as part of medical care, and client-initiated or voluntary testing and counseling (VCT) [6]. Empirical evidence has demonstrated the public health benefits of HIV testing such as reduction in risky sexual behaviour $[7,8]$ and linking HIV infected individuals to HIV care, treatment and support $[9,10]$. In Africa, however, low access and limited reach of facilitybased HIV testing services have been an impediments to global attempts to prevent HIV transmission and scaleup of HIV care and treatment at population level [11].

Home-Based HIV Counseling and Testing (HBHCT) has the potential to address the challenges of limited access to testing. It involves the use of mostly
C Biomed Central 
community health workers to provide door-to-door counseling and testing services to consenting members of the community [12]. HBHCT has been shown to increase uptake of HIV testing, improve access to testing, while simultaneously limiting the costs for travelling to health facilities and reducing the potential stigma $[8,12,13]$. Uganda relies heavily on the conventional facility-based HIV testing models in line with the national policy recommendations [14], but these approaches mostly reach patients visiting health facilities or individuals who seek voluntary HIV testing following known exposure to HIV infection $[15,16]$.

Although HBHCT may be effective in increasing access of HIV testing, a recent systematic review suggested that there is limited evidence and experience to support widespread scale-up of implementation of this model in Sub-Saharan Africa [11]. Few published studies have evaluated the feasibility, acceptance and uptake of HBHCT in rural $[8,9,17]$ and in mixed rural-urban populations in Uganda [18]. Urban community residents represent a unique risk subgroup for HIV as evidenced by patterns of higher HIV sero-prevalence in urban compared to rural settings $[19,20]$. This pilot study was done to evaluate further the acceptance of HBHCT, to estimate the HIV sero-prevalence among individuals tested at home, and to determine the factors associated with acceptance of HBHCT in an urban setting. The information generated will add to the body of knowledge towards community-based interventions for HIV testing in urban settings.

\section{Methods}

\section{Study Setting and Population}

A cross-sectional house-to-house survey was nested in an ongoing community cough survey conducted in Rubaga division of Kampala city from January-June 2009. The division has a population of about 250,000 people, with $50 \%$ adults 15 years or older. It is composed of 13 administrative units called parishes which are further subdivided into 127 smaller units called local council villages or zones [21]. The division is mainly served by two private not-for-profit hospitals, two public health care clinics and is also proximal to the national referral hospital. All these health facilities offer provider-initiated HIV testing as part of routine medical care routine. However, HIV testing services are also available for a minimal cost at other stand-alone voluntary HIV counseling and testing centers in Kampala. Almost all participants resided no more than approximately 5-10 kilometers from at least one of the health facilities.

\section{Eligibility Criteria}

Adults aged 15 years and older who were residents of Rubaga division were eligible to enrol in the study. We excluded persons who already knew their HIV status to be positive, those who were not able to communicate in English or Luganda, who did not give written consent to participate or who were absent from home at the time of survey. The study was approved by the Makerere University School of Public Health Research and Ethics committee and the Uganda National Council for Science and Technology.

\section{Sampling}

Rubaga division was conveniently selected for the study because of its proximal location $(\sim 10 \mathrm{Km})$ to the Mulago National Referral Hospital which offers free comprehensive HIV/AIDS testing and treatment services. A computer-based random number generator was used randomly select five villages for the study. The total numbers of subjects to enroll per village were estimated using the proportion-to-population size approach. The specific houses within the selected villages were also selected randomly using an approach that was previously employed in a similar setting and described in detail elsewhere [22]. Eligible participants who were found at home were consecutively enrolled from the selected households at the time of the study visit. The five villages included in the study were similar in their population characteristics.

\section{Study Outcomes}

The main study outcome was acceptance of HIV test which was operationalized as consenting, actually taking the test and receiving test results offered in the participants' home. The secondary outcome was the HIV seroprevalence defined as participants who had a positive rapid HIV test result out of those who had a test performed.

\section{Data Collection}

During the home visits a trained study team of six; three nurse counselors and three interviewers worked in pairs to obtain written informed consent, administered face-to-face interviews and, performed HIV testing. The information gathered included sociodemographics, occupation, weekly income, previous HIV test history, knowledge if current HIV status and, willingness to accept an HIV test. Quality assurance principles of counseling were observed before, during and after the HIV test in accordance with the national $\mathrm{HV}$ policy guidelines [14]. Eligible members of the same household were offered the options of individual or group pre-test counseling. For household members who preferred group counseling, the study counselors provided the standard HIV information about testing in one seating after which they were requested to give written consent to be tested. Post-test counseling and 
delivery of results was offered according to the participants' preference.

\section{Home-Based HIV Testing Procedures}

Rapid HIV testing was performed according to the testing algorithm recommended by the Uganda national HIV testing policy [14]. Determine HIV-1/2 assay (Abbott Laboratories, Illinois, United States of America) was used for screening, the HIV-1/2 STAT-PAK Dipstick assay (Chembio Diagnostic System Inc, New York, USA) was used as the confirmatory test and the UniGold test (Trinity Biotech, Wicklow, Ireland) as the tiebreaker. The results were reported as positive if the Uni-gold test results were positive. The average test result turnaround was 15-20 minutes.

\section{Referral for Care and Medical Evaluation}

Participants who were identified to be HIV sero-positive during the survey were advised to seek further evaluation and referred to HIV care centres of their preference. Individuals who tested HIV negative received HIV prevention counseling. The interviewers also encouraged participants to disclose their HIV status to their sexual partners and/or family members as they felt comfortable.

\section{Statistical Analysis}

The main outcome was coded as a binary variable (HIV test acceptance, 'Yes' or 'No'). Acceptance was expressed as the proportion (with $95 \%$ confidence intervals) of participants who voluntarily accepted and took the HIV test among those who were offered a test. The HIV seroprevalence was estimated among those who accepted to be tested from the HBHCT as the proportion who were HIV sero-positive. Differences in proportions among groups for the unordered categorical variables were tested with Pearson's chi-square; trends in proportions of ordered categorical variables were tested for using the Cochran-Armitage test. Multivariable logistic regression analysis was used to determine factors that were associated with acceptance of HBHCT. The best prediction model was selected based on a measure of model goodness of fit, the Akaike Information Criterion (AIC) [23]. Factors included in the analysis were sex, age, religion, education, marital status and previous HIV testing. All chi-square $\mathrm{P}$-values $\leq 0.05$ were considered statistically significant. Data management and analysis was done using Statistical Analysis Software (SAS) and cross-validated using STATA (version 11.0; StataCorp, LLC, College Station, TX, USA).

\section{Results}

Between January and June, 2009, 444 households comprising 698 potential participants were surveyed by the study counselor-interviewer teams. Of the 698 individuals, 588 (84\%) were successfully enrolled on the study (Figure 1). Individuals who did not respond $(n=110$; $16 \%$ ) were not at home at the time of the survey or declined to participate. There was $100 \%$ response rate on all items in the questionnaire. All participants who accepted to take the HIV test underwent post-test counseling and received their test results.

\section{Description of Study Participants}

Participation was skewed towards women as only $22 \%$ of the sample was men. The median age was 23 years (IQR $=10$ ), with the majority (58\%) in the age group 15-24 years [Table 1]. Nearly half $(48 \%)$ of the participants were currently married and the majority identified themselves as Christians. More than half (53\%) had attained at least 7-13 years of formal education) and had a relatively low average weekly income of not more than five thousand Uganda shillings ( 2.00 USD). About twothirds of the of the study participants self reported as ever had an HIV test, with the majority reporting having had a test within the past twelve months. However, 39\% of the participants had never tested for HIV; this roughly reflects the unmet need for HIV testing at that time in this community.

\section{Acceptance of Home-Based HIV testing}

Among participants enrolled in the study, 408 (69\%, 95\% CI: 66\%-73\%) accepted home-based HIV counseling and testing. The distribution of baseline characteristics for participants who accepted and those who did not accept differed by age $(\mathrm{p}=0.012)$, marital status $(\mathrm{p}=$ $0.017)$, education level $(p=0.043)$ and previous HIV test history $(\mathrm{p} \leq 0.0001)$. The proportion of participants who accepted an HIV test in the home was lower for those who had never been tested previously compared with those who had tested in the past ( $58 \%$ vs. $85 \%$ ). The two groups were similar in sex and religion distribution ( $\mathrm{p}=0.112$ and 0.171$)$ [Table 2].

\section{Factors Associated with Home-based HIV test Acceptance}

In a multivariable logistic regression analysis, sex, age, marital status and previous HIV test history were significantly associated with acceptance of HIV testing [Table 3]. Males were nearly twice as likely to accept the HIV test compared to females [adjusted OR: 1.67, 95\% CI: 1.032.73]. Participants in age groups $25-34$ and 35 years or older were less likely to accept the HIV test as compared with younger adults aged 15-24 years. Participants who were previously married were more than three times more likely to accept the HIV test when compared with those who were never married. People who reported to have previously tested for HIV within 12 months were less likely to accept the HIV test when compared with those 


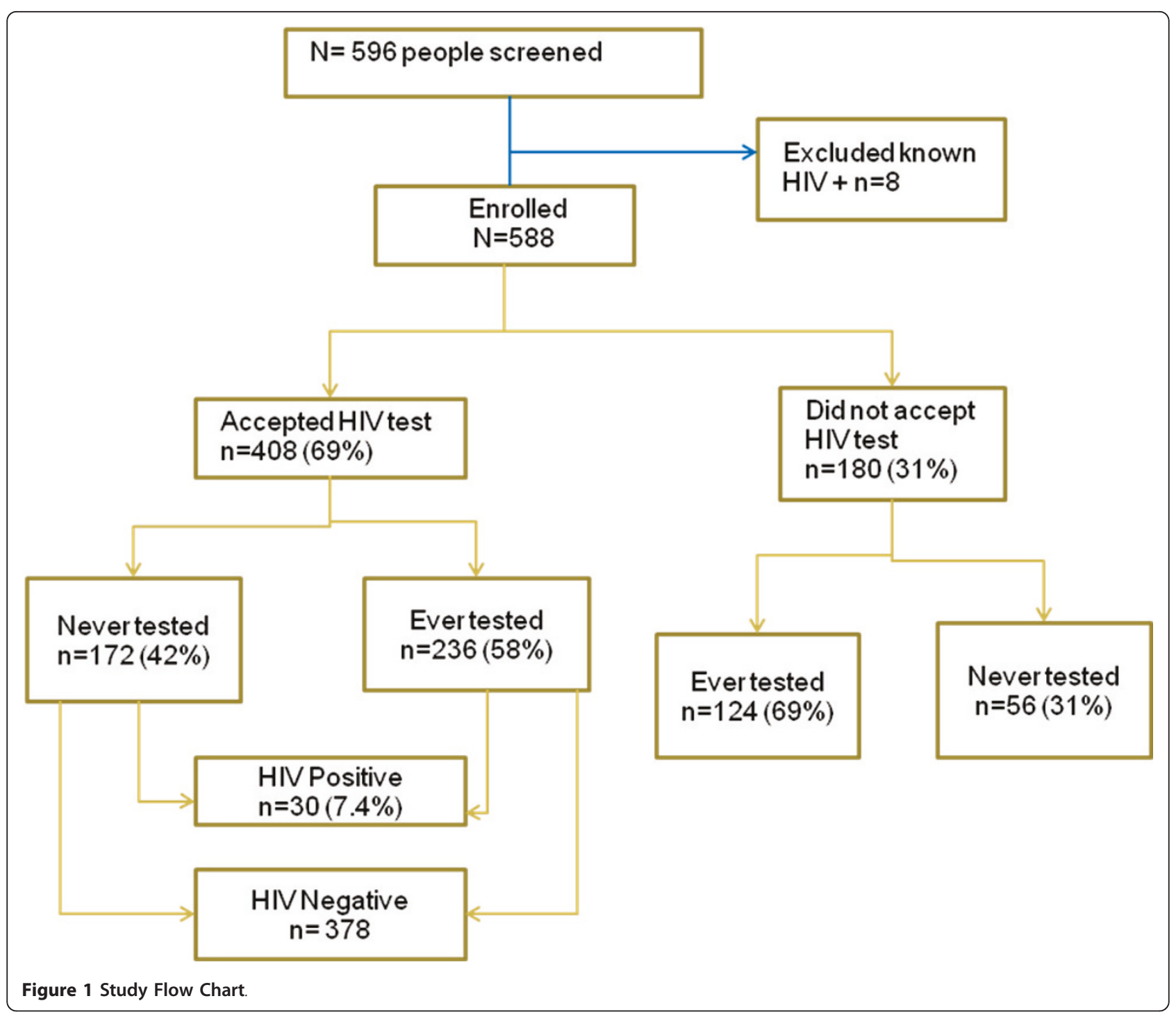

who had never tested. Those who had tested more than 12 months prior were more likely to accept the test compared to those who had never tested although the association was not statistically significant.

\section{HIV Sero-Prevalence among Participants who Accepted Home-Based HIV Testing}

Home-based HIV testing identified 30 [7.4\%, 95\% CI: 4.8\%-9.9\%] previously undetected HIV cases among the 408 participants who accepted the test. However the estimated HIV sero-prevalence was 6.5\% (95\% CI: 4.58.5\%] for the entire study sample including eight people who were already known to be HIV positive. The majority of those who were found to be HIV sero-positive were young adults 15-24 years, female, married, of very low education level [Table 4]. Most had "never tested" for HIV in the past, though nearly one-third of the newly detected HIV sero-positive individuals had taken an HIV test within 12 months prior of the home-based testing survey. There were no significant differences in baseline characteristics between participants that tested HIV sero-positive and those that tested sero-negative except for marital status. The most predominant reason for not accepting home-based testing was having taken a test within 6 months prior to the survey, (33.3\%). Other reasons included fear or not being emotionally ready to take an HIV test (19.4\%), wanting to first seek approval of a spouse or parent (9.4\%), not being interested in taking a test $(18.9 \%)$ or not being sexually active (7.2\%), these numbers are not presented in the table.

\section{Discussion}

We found that home-based HIV counseling and testing was feasible and acceptable (69\%) in this urban setting 
Table 1 Baseline Characteristics of Participants in HomeBased HIV Testing in Rubaga, Kampala (January - June 2009)

\begin{tabular}{|c|c|c|}
\hline Characteristics & Frequency $\mathrm{N}=588$ & Percent \\
\hline \multicolumn{3}{|l|}{ Age, yrs* } \\
\hline $15-24$ & 337 & 58 \\
\hline $25-34$ & 167 & 28 \\
\hline$\geq 35$ & 84 & 14 \\
\hline \multicolumn{3}{|l|}{ Sex } \\
\hline Female & 456 & 78 \\
\hline Male & 132 & 22 \\
\hline \multicolumn{3}{|l|}{ Marital status } \\
\hline Never married & 235 & 40 \\
\hline Currently married & 281 & 48 \\
\hline Previously married & 72 & 12 \\
\hline \multicolumn{3}{|l|}{ Religion } \\
\hline Catholic & 161 & 27 \\
\hline Protestant & 161 & 27 \\
\hline Muslim & 141 & 24 \\
\hline Others ${ }^{* *}$ & 125 & 22 \\
\hline \multicolumn{3}{|l|}{ Education level } \\
\hline None-Primary & 221 & 38 \\
\hline Secondary & 312 & 53 \\
\hline College/University & 55 & 9 \\
\hline \multicolumn{3}{|l|}{ Weekly Incomet } \\
\hline None & 145 & 25 \\
\hline > 0-5000 (Ugshs) & 237 & 40 \\
\hline$\geq 5000$ & 206 & 35 \\
\hline \multicolumn{3}{|l|}{ Ever had an HIV test } \\
\hline Yes & 360 & 61 \\
\hline$\leq 12$ months & 216 & 37 \\
\hline$>12$ months & 144 & 26 \\
\hline
\end{tabular}

* Mean (SD) = 26 (8.9), Median Age (IQR) = $23(19,29)$

** Other -(Pentecostal, Seventh day Adventist or religion not specified)

† Median weekly income $=$ UGSH 4,000 ( US\$2.00)

in Kampala. The factors associated with acceptance of HIV counseling and testing in the home were being 25 years or older, being male, previously married and previous HIV testing history. The HIV sero-prevalence in the study population was similar to the most recent national HIV sero-prevalence estimate of 6.4\% [24]. These findings were consistent with population-based studies done elsewhere that showed high acceptance for home-based HIV counseling and testing $[3,25]$. However, we did not find any published quantitative urban population-based studies for Uganda.

Our study findings support the use of a home-based HIV counseling and testing strategy in an urban setting. Urban population-based studies done in Zambia and Kenya reported similar acceptance levels; $71 \%$ and $78 \%$ of participants agreed to HIV testing and counseling in the home, respectively $[3,25]$. In contrast, rural population-based studies done in Africa consistently showed higher levels of acceptance for home-based HIV counseling and testing ranging from $84 \%$ to $98 \%[12,17,26]$. The urban-rural differences in acceptance for homebased HIV counseling and testing could be due to underlying disparities in availability and access to testing sites. Regardless of the contextual factors, the high demand for home-based HIV testing suggests that this strategy could potentially address known barriers associated with facility-based HIV testing including stigma, discrimination, fear to receive results, lack of confidentiality, privacy, long distances and cost of transportation to testing sites $[5,9,13,16]$. Based on the reasons given by those individuals for not accepting to take the homebased test in our study such as not being emotionally prepared and having to consult spouses or parents, it is evident that HIV programs would still need to be aware of existing barriers and seek to address them.

Like other studies [25], we found that men were more likely to accept the test than women during this homebased survey. Differences in gender $r$ roles may explain some of the results in this study. Women of reproductive age are more likely than men to come into frequent contact with the health system and thus to access HIV testing services. For example, pregnant women have an opportunity to learn their HIV sero-status through the routine testing during Antenatal Care and Prevention of Mother-to-Child HIV transmission programs [19]. On the other hand, the higher acceptance of HBHCT by men presents an opportunity to reach entire families through community-based approaches. From a social-cultural perspective, targeting married men with home-based HIV counseling and testing could be beneficial for promoting couple counseling and testing [10]. In Uganda, men often play a dominant role in the decision making process related to couple and family health issues.

Consistent with a similar study done in Malawi [27], socio-demographic factors also influence acceptance of home-based HIV testing, older individuals were less likely to accept a home-based HIV test compared to younger individuals. A possible explanation is that older individuals are usually married or in stable relationships and may have a lower HIV risk perception. However, previously married (widowed or separated) individuals were more likely to accept the HIV test; perhaps motivated by a higher risk perception for HIV infection in this subgroup. In Uganda, being widowed often results from death of spouse from HIV/AIDS [27] and has been shown to be a risk factor for HIV infection [20]. Previous testing especially within 12 months prior to the HBHCT was negatively associated with acceptance compared with individuals never previously tested. The Uganda HIV testing policy recommends repeating an HIV testing within six months of a previous test [14] but there is need to be a more practical strategy for its implementation. 
Table 2 Bivariate Analysis of Factors Associated with Acceptance of HIV Testing in Kampala, Uganda N = 588

\begin{tabular}{|c|c|c|c|c|}
\hline Characteristics & $\begin{array}{l}\text { Accepted HIV testing N }=408 \\
(69 \%) n(\%)\end{array}$ & $\begin{array}{l}\text { Did not Accept HIV testing } \mathrm{N}= \\
180 \mathrm{n}(\%)\end{array}$ & $\begin{array}{l}\text { Pearson } X^{2} P- \\
\text { value }\end{array}$ & $\begin{array}{l}\text { Unadjusted OR } \\
(95 \% \mathrm{Cl})\end{array}$ \\
\hline \multicolumn{5}{|l|}{ Sex } \\
\hline Female & $309(76)$ & $147(82)$ & & 1.00 \\
\hline Male & $99(24)$ & $33(18)$ & 0.112 & $1.43(0.92-2.22)$ \\
\hline \multicolumn{5}{|l|}{ Age, yrs } \\
\hline 15-24 & $245(60)$ & $92(51)$ & & 1.00 \\
\hline $25-34$ & $114(28)$ & $53(29)$ & & $0.81(0.54-1.21)$ \\
\hline$>=35$ & $49(12)$ & $35(20)$ & $0.012^{*} \dagger$ & $0.53(0.32-0.86)$ \\
\hline \multicolumn{5}{|l|}{ Marital status } \\
\hline Never Married & $169(41)$ & $66(37)$ & & 1.00 \\
\hline currently & $181(44)$ & $100(56)$ & & $0.71(0.49-1.03)$ \\
\hline Previously & $58(15)$ & $14(7)$ & $0.017^{*}$ & $1.62(0.85-3.00)$ \\
\hline \multicolumn{5}{|l|}{ Religion } \\
\hline Catholic & $112(27)$ & $49(27)$ & & 1.00 \\
\hline Protestant & $109(26)$ & $52(39)$ & & $0.92(0.57-1.47)$ \\
\hline Muslim & $91(23)$ & $50(28)$ & & $0.80(0.49-1.29)$ \\
\hline Other & $96(24)$ & $29(16)$ & 0.171 & $1.45(0.85-2.47)$ \\
\hline \multicolumn{5}{|l|}{$\begin{array}{l}\text { Education level (yrs of } \\
\text { school) }\end{array}$} \\
\hline None - Primary & $164(40)$ & $57(32)$ & & 1.00 \\
\hline Secondary & 209(51) & $103(57)$ & & $0.71(0.48-1.03)$ \\
\hline College/University & $35(9)$ & $20(11)$ & $0.043^{*}+$ & $0.61(0.33-1.14)$ \\
\hline \multicolumn{5}{|l|}{ Ever had HIV test } \\
\hline No & $172(42)$ & $56(31)$ & & 1.00 \\
\hline \multicolumn{5}{|l|}{ Yes } \\
\hline$\leq 12$ months & $125(31)$ & $91(51)$ & & $0.45(0.30-0.67)$ \\
\hline$>12$ months & $111(27)$ & $33(18)$ & $<0.0001^{*}$ & $1.10(0.067-1.79)$ \\
\hline
\end{tabular}

$\$$ Other -(Pentecostal, Seventh day Adventist or unspecified religion)

*significant at $\mathrm{P} \leq 0.05+$ trend $\mathrm{P}$ value (Cochran-Armitage)

The HIV sero-prevalence in the overall study population was $6.5 \%$ while the sero-prevalence among those who accepted to test was $7.4 \%$. These findings are very similar to the national sero-prevalence of $6.4 \%$ and provides external validity to our study [28]. A lower proportion of individuals self-reported as previously "never tested" (39\%) compared to 55\%-65\% national estimates for 15-49 year old urban residents [19]. Furthermore, a high proportion of previously "never tested" individuals were HIV seropositive. Similarly, a study done in rural western Uganda was effective in identifying previously unknown HIV positive individuals as well as discordant couples among those who had "never tested" [17]. Since Uganda's HIV epidemic has reached a stable and generalized state, it is critical to identify the hidden drivers for effective infection prevention and control. This study and others $[1,9,17]$ point to the potential value of home-based HIV counseling and testing as a way to reach untested individuals.

The WHO/UNAIDS policy guidelines recommends four key strategies for HIV counseling and testing that are mainly facility-based [16]. However, it is apparent that complementary strategies such as home based HIV counseling and testing that expand access to HIV testing services in underserved or hard to reach communities are needed. Such strategies could enhance early identification of HIV positive individuals, prompt linkage to treatment and care, and may curtail risky sexual behaviours that lead to HIV transmission [29]. The successful Implementation of HBHCT could be hampered by shortage of trained health workers and high operational costs in resource limited settings. In order to circumvent such challenges, delivery models that leverage community resources such as trained community lay providers who can perform rapid HIV testing under supervision by medical personnel, have been used elsewhere [12] and are also endorsed by the Uganda HIV policy guidelines [14]. Integration of HBHCT with other community screening programs such as those for tuberculosis and/or malaria may also increase cost-effectiveness [13].

\section{Study Limitations}

Our study findings should be interpreted in light of some limitations. First, the sero-prevalence of the study could be an underestimate because we are missing 
Table 3 Multivariable Regression Analysis of Factors Associated with Acceptance of HIV Testing in Kampala, Uganda $\mathbf{N}=\mathbf{5 8 8}$

\begin{tabular}{|c|c|c|}
\hline Characteristics & $\begin{array}{l}\text { Accepted HIV testing } N=408 n \\
(\%)\end{array}$ & $\begin{array}{l}\text { Adjusted OR } \\
(95 \% \mathrm{Cl})\end{array}$ \\
\hline \multicolumn{3}{|l|}{ Sex } \\
\hline Female & 309(76) & 1.00 \\
\hline Male & $99(24)$ & $1.67(1.03-2.73)$ \\
\hline \multicolumn{3}{|l|}{ Age, yrs } \\
\hline 15-24 & $245(60)$ & 1.00 \\
\hline $25-34$ & $114(28)$ & $0.63(0.40-0.94)$ \\
\hline$>=35$ & $49(12)$ & $0.30(0.17-0.56)$ \\
\hline \multicolumn{3}{|l|}{ Marital status } \\
\hline $\begin{array}{l}\text { Never } \\
\text { married }\end{array}$ & $169(41)$ & 1.00 \\
\hline Currently & $181(44)$ & $1.25(0.75-1.93)$ \\
\hline Previously & $58(15)$ & $3.22(1.49-6.98)$ \\
\hline \multicolumn{3}{|l|}{$\begin{array}{l}\text { Ever had HIV } \\
\text { test }\end{array}$} \\
\hline No & $172(42)$ & 1.00 \\
\hline \multicolumn{3}{|l|}{ Yes } \\
\hline $\begin{array}{l}\leq 12 \\
\text { months }\end{array}$ & $125(31)$ & $0.50(0.30-0.74)$ \\
\hline $\begin{array}{l}>12 \\
\text { months }\end{array}$ & $111(27)$ & $1.28(0.75-2.19)$ \\
\hline
\end{tabular}

information about the individuals who did not accept the HIV test. If we apply the estimated $6.4 \%$ sero-prevalence to our study sample then we would have expected a slightly higher HIV prevalence. We also excluded children younger than 15 years; therefore our findings can only be generalized to the adult population in similar urban settings. Second, there is selection bias as the study population comprises mostly women; this may lead to an overestimation of the HIV sero-prevalence because women are at a greater risk for HIV than men [20]. The strength of this study is that it was conducted in the general urban population which gives a picture of the operational experiences and challenges that could be encountered when HBHCT is undertaken in similar settings. Previous community HIV testing has been mainly targeted towards high risk household members of already known HIV/AIDS infected or tuberculosis index cases [10].

\section{Conclusions}

Acceptance of home-based counseling and testing was relatively high in this urban setting. This strategy provided access to HIV testing for previously untested and unknown HIV-infected individuals in the community. Age, sex, marital status and previous HIV test history

Table 4 HIV Sero-Prevalence Among 408 Adults Who Accepted Home-based Testing in Kampala: January - June, 2009

\begin{tabular}{|c|c|c|c|}
\hline Characteristic & HIV positive $n=30(7.4 \%)$ & HIV negative $n=378(\%)$ & Chi-sq $\mathrm{P}$ \\
\hline \multicolumn{4}{|l|}{ Age, yrs } \\
\hline $15-24$ & $16(53)$ & $229(61)$ & \\
\hline $25-34$ & $8(27)$ & $106(28)$ & \\
\hline$\geq 35$ & $6(20)$ & $43(11)$ & 0.370 \\
\hline \multicolumn{4}{|l|}{ Sex } \\
\hline Female & 25(83) & $284(75)$ & \\
\hline Male & $5(17)$ & $94(25)$ & 0.313 \\
\hline \multicolumn{4}{|l|}{ Marital Status } \\
\hline Never Married & $6(20)$ & $163(43)$ & \\
\hline Previously Married & $8(27)$ & $50(13)$ & \\
\hline Married & $16(53)$ & $165(44)$ & 0.021 \\
\hline \multicolumn{4}{|l|}{ Religion } \\
\hline Catholic & $11(37)$ & $101(27)$ & \\
\hline Protestant & $7(23)$ & $102(27)$ & \\
\hline Muslim & $6(20)$ & $85(22)$ & \\
\hline Other & $6(20)$ & $90(24)$ & 0.708 \\
\hline \multicolumn{4}{|c|}{ Education level (yrs of school) } \\
\hline None - Primary & $17(57)$ & $147(39)$ & \\
\hline Secondary & $11(37)$ & $198(52)$ & \\
\hline College/University & $02(6)$ & 33(9) & 0.160 \\
\hline \multicolumn{4}{|l|}{ Ever had HIV Test } \\
\hline Never tested & $13(43)$ & $159(42)$ & \\
\hline$\leq 12$ months & $9(30)$ & $116(31)$ & \\
\hline$>12$ months & $8(27)$ & $103(27)$ & 0.268 \\
\hline
\end{tabular}


are important factors that may be considered when designing programs for home-based HIV testing in urban settings in Uganda.

\section{Acknowledgements}

The authors would like to acknowledge the funding support of the Doris Duke Charitable Foundation. We thank the staff of Uganda-Case Western Reserve University Research Collaboration, particularly Yusuf Mulumba and LaShonda Malone for their skilful data management of the project, and Dr. Sarah Zalwango for her technical support to the Doris Duke community study. We acknowledge the study home health visitors and interviewers; Josylene Nabisere, Joyce Nalubowa, Joan Nassuna, Esther Nakayenga and Godfrey Kijjambu who worked very hard to enrol community participants. We would like to thank the Rubaga community local leaders for their administrative support and the residents who volunteered their time to participate in the study.

\section{Author details}

${ }^{1}$ College of Public Health, University of Georgia, Athens, GA, USA. ${ }^{2}$ School of Public Health, College of Health Science, Makerere University, Kampala, Uganda. ${ }^{3}$ Yale Primary Care Program, Yale University School of Medicine, New Haven, CT, USA. ${ }^{4}$ Uganda Case Western Research Collaboration, Kampala, Uganda.

\section{Authors' contributions}

JNS: Designed the study, coordinated recruitment of participants, collected data, analyzed data and drafted the manuscript. CCW: Designed the study, participated in data analysis and reviewed all drafts of the manuscript. HS: Designed the study, participated in data collection, analysis, and reviewed all drafts of the manuscript. JL: Designed the study, coordinated recruitment of participants, collected data, analyzed data and reviewed drafts of the manuscript. AS: Participated in design, data analysis and reviewed all draft manuscript. MA: Participated in design, data collection, analysis, reviewed drafts of the manuscript. XY: Guided and help with data analysis, reviewed drafts of the manuscript. All authors read and approved the final manuscript.

\section{Competing interests}

The authors declare that they have no competing interests.

Received: 24 May 2011 Accepted: 26 September 2011

Published: 26 September 2011

\section{References}

1. Menzies N, Abang B, Wanyenze R, Nuwaha F, Mugisha B, Coutinho A, Bunnell R, Mermin J, Blandford JM: The costs and effectiveness of four HIV counseling and testing strategies in Uganda. AIDS 2009, 23(3):395-401.

2. Wanyenze RK, Nawavvu C, Namale AS, Mayanja B, Bunnell R, Abang B, Amanyire G, Sewankambo NK, Kamya MR: Acceptability of routine HIV counselling and testing, and HIV seroprevalence in Ugandan hospitals. Bull World Health Organ 2008, 86(4):302-309.

3. Irungu TK, Varkey P, Cha S, Patterson JM: HIV voluntary counselling and testing in Nakuru, Kenya: findings from a community survey. HIV Med 2008, 9(2):111-117.

4. Nakanjako D, Kamya M, Daniel K, Mayanja-Kizza H, Freers J, Whalen C, Katabira E: Acceptance of routine testing for HIV among adult patients at the medical emergency unit at a national referral hospital in Kampala, Uganda. AIDS Behav 2007, 11(5):753-758.

5. Matovu JK, Makumbi FE: Expanding access to voluntary HIV counselling and testing in sub-Saharan Africa: alternative approaches for improving uptake, 2001-2007. Trop Med Int Health 2007, 12(11):1315-1322.

6. World Health Organization HAD: Towards universal access: Scaling up priority HIV/AIDS interventions in the health sector. Geneva, Switzerland: WHO; 2010.

7. De Zoysa I, Phillips KA, Kamenga MC, O'Reilly KR, Sweat MD, White RA, Grinstead OA, Coates TJ: Role of HIV counseling and testing in changing risk behavior in developing countries. AIDS 1995, 9(Suppl A):S95-101.
8. Wolff B, Nyanzi B, Katongole G, Ssesanga D, Ruberantwari A, Whitworth J: Evaluation of a home-based voluntary counselling and testing intervention in rural Uganda. Health Policy Plan 2005, 20(2):109-116.

9. Were W, Mermin J, Bunnell R, Ekwaru JP, Kaharuza F: Home-based model for HIV voluntary counselling and testing. Lancet 2003, 361(9368):1569.

10. Were WA, Mermin JH, Wamai N, Awor AC, Bechange S, Moss S, Solberg P, Downing RG, Coutinho A, Bunnell RE: Undiagnosed HIV infection and couple HIV discordance among household members of HIV-infected people receiving antiretroviral therapy in Uganda. J Acquir Immune Defic Syndr 2006, 43(1):91-95.

11. Bateganya MH, Abdulwadud OA, Kiene SM: Home-based HIV voluntary counseling and testing in developing countries. Cochrane Database Syst Rev 2007, , 4: CD006493.

12. Negin J, Wariero J, Mutuo P, Jan S, Pronyk P: Feasibility, acceptability and cost of home-based HIV testing in rural Kenya. Trop Med Int Health 2009, 14(8):849-855.

13. Escobar MC: Home-Based HIV Counseling and testing: Program Components and Approaches. Technical Consultaion Report. Arlington, VA: USAID/AIDSTAR-ONE Project, Task Order l; 2010.

14. Uganda Ministry of Health: Uganda National Policy Guidelines for HIV counseling and Testing. Kampala:: Ministry of Health; 2003.

15. Bwambale FM, Ssali SN, Byaruhanga S, Kalyango JN, Karamagi CA: Voluntary HIV counselling and testing among men in rural western Uganda: implications for HIV prevention. BMC Public Health 2008, 8:263.

16. UNAIDS/WHO: Policy Statement on HIV Testing. 2004

17. Tumwesigye E, Wana G, Kasasa S, Muganzi E, Nuwaha F: High uptake of home-based, district-wide, HIV counseling and testing in Uganda. AIDS patient Care STDS 2010, 24(11):735-741.

18. Yoder PS, Katahoire RAnne, Kyaddondo David, Akol Zainab, Bunnell Rebecca, Frank Kaharuza: Home-Based HIV Testing and Counselling in a Survey Context in Uganda. Calverton, Maryland, USA: ORC Macro; 2006.

19. Uganda Bureau of Statistics (UBOS): Uganda Demographic and Health Survey (UDHS). Kampala; 2006.

20. Mermin J, Musinguzi J, Opio A, Kirungi W, Ekwaru JP, Hladik W, Kaharuza F, Downing $\mathrm{R}$, Bunnell R: Risk factors for recent HIV infection in Uganda. JAMA 2008, 300(5):540-549.

21. Uganda Bureau of Statistics (UBOS): 2002 Uganda Population and Housing Census. 2006

22. Sekandi JN, Neuhauser D, Smyth K, Whalen CC: Active case finding of undetected tuberculosis among chronic coughers in a slum setting in Kampala, Uganda. Int J Tuberc Lung Dis 2009, 13(4):508-513.

23. Akaike $\mathrm{H}$ : "A new look at the statistical model identification". IEEE Transaction on Automatic Control 1974, 19(6):716-723.

24. Hladik W, Musinguzi J, Kirungi W, Opio A, Stover J, Kaharuza F, Bunnell R, Kafuko J, Mermin J: The estimated burden of HIV/AIDS in Uganda, 20052010. AIDS 2008, 22(4):503-510.

25. Mutale W, Michelo C, Jurgensen M, Fylkesnes K: Home-based voluntary HIV counselling and testing found highly acceptable and to reduce inequalities. BMC Public Health 2010, 10:347.

26. Obare F, Fleming P, Anglewicz P, Thornton R, Martinson F, Kapatuka A, Poulin M, Watkins S, Kohler HP: Acceptance of repeat population-based voluntary counselling and testing for HIV in rural Malawi. Sex Transm Infect 2009, 85(2):139-144.

27. Helleringer S, Kohler HP, Frimpong JA, Mkandawire J: Increasing uptake of HIV testing and counseling among the poorest in sub-Saharan countries through home-based service provision. J Acquir Immune Defic Syndr 2009, 51(2):185-193.

28. UNAIDS: Report on the global AIDS epidemic. 2010

29. Bunnell R, Opio A, Musinguzi J, Kirungi W, Ekwaru P, Mishra V, Hladik W, Kafuko J, Madraa E, Mermin J: HIV transmission risk behavior among HIVinfected adults in Uganda: results of a nationally representative survey. AIDS 2008, 22(5):617-624

\section{Pre-publication history}

The pre-publication history for this paper can be accessed here: http://www.biomedcentral.com/1471-2458/11/730/prepub

doi:10.1186/1471-2458-11-730

Cite this article as: Sekandi et al:: High acceptance of home-based HIV counseling and testing in an urban community setting in Uganda. BMC Public Health 2011 11:730. 